\title{
Efecto antimicrobiano de aditivos naturales en carne de cerdo cruda
}

\author{
Antimicrobial effect of natural additives into pork raw meat
}

\author{
María J. Graciano-Cristóbal ${ }^{1}$, María T. Sumaya-Martínez ${ }^{2 *}$, Rosendo Balois-Morales ${ }^{2}$, \\ Javier G. Rodríguez-Carpena², Edgar I. Jiménez-Ruiz², Pedro U. Bautista-Rosales², \\ Eduardo O. Madrigal-Santillán ${ }^{3}$
}

\section{RESUMEN}

Una alternativa para reducir el crecimiento microbiano en productos cárnicos almacenados en refrigeración es el uso de aditivos comestibles elaborados con base en especias culinarias, así como cálices de jamaica verde y jugo de limón. El objetivo de este estudio fue evaluar el efecto antibacteriano de tres aditivos comestibles (aditivo 1: cebolla, cilantro, orégano, jugo de limón, mezcla de canela-clavo; aditivo 2: cebolla, cilantro, hojas de laurel, jugo de limón, mezcla de canela-clavo; aditivo 3: cebolla, cilantro, pimienta negra, chile verde, ajo, sal, cálices de Jamaica verde, jugo de limón, mezcla de canela-clavo), sobre el crecimiento de Escherichia coli O157:H7 en hamburguesas de carne de cerdo cruda almacenadas a $4{ }^{\circ} \mathrm{C}$ durante 12 días. Los resultados experimentales señalan que el aditivo 3 logró reducir de forma significativa ( $p \leq 0.05)$ el crecimiento de una alta concentración de E. Coli $(105 \mathrm{UFC} / \mathrm{mL})$ en las hamburguesas, aun diluyéndolo a $50 \%$ de su concentración original.

PALABRAS CLAVE

especias culinarias, aditivos comestibles, actividad antimicrobiana, Escherichia coli O157:H7

\section{ABSTRACT}

An alternative to reduce microbial growth in meat products stored in refrigeration is the use of edible additives made from culinary spices, and green jamaica chalices and lemon juice. The objective of this study was to evaluate the antibacterial effect of three edible additives (additive 1: onion, cinnamon, coriander, lemon juice, cinnamon-clove mix; additive 2: onion, coriander, laure leaves, lemon juice, cinnamon-clove mix; additive 3: onion, coriander, black pepper, green chili, garlic, salt, green hibiscus calyx, lemon juice, cinnamon-clove mix), on the growth of Escherichia coli O157: $\mathrm{H} 7$ in raw pork burgers stored at $4{ }^{\circ} \mathrm{C}$ for 12 days. The experimental results indicate that additive 3 significantly reduced the growth of a high concentration of $E$. Coli (105 UFC/mL) in hamburgers, even at $50 \%$ of its original concentration.

KEYWORDS

culinary spices, edible additives, antimicrobial activity, Escherichia coli O157:H7

\footnotetext{
${ }^{1}$ Unidad Académica de Agricultura, Universidad Autónoma de Nayarit. Xalisco, Nayarit, México.

${ }^{2}$ Secretaría de Investigación y Posgrado, Universidad Autónoma de Nayarit. Tepic, Nayarit, México.

${ }^{3}$ Laboratorio de Medicina de Conservación, Escuela Superior de Medicina. Ciudad de México, México.

* Autor para correspondencia. Ciudad de la Cultura "Amado Nervo". 63155 Tepic, Nayarit, México.

Correo electrónico: teresumaya@hotmail.com
} 


\section{INTRODUCCIÓN}

La conservación de los productos alimenticios frente a la degradación causada principalmente por procesos de oxidación o actividad de microorganismos durante la producción, el almacenamiento y la distribución es un tema importante para la industria alimentaria (Viuda-Martos et al., 2010), debido al impacto negativo que ésta puede causar en el aspecto sensorial del alimento o en la salud del consumidor.

Las enfermedades trasmitidas por los alimentos (ETA) han sido siempre una preocupación importante a nivel mundial (Mead et al., 1999). Campylobacter jejuni, Staphylococcus aureus, Salmonella, Escherichia coli, Streptococcus, entre otras, son algunas de las especies principales bacterianas que causan ETA (USDA, 1997). Escherichia coli enterohemorrágica (ECEH) es una de las bacterias patógenas de mayor cuidado hoy en día debido a su facilidad de propagación y a los padecimientos que provoca. La infección por ECEH puede conducir al síndrome hemolítico urémico, que daña las células sanguíneas, conduce a insuficiencia renal e incluso a la muerte (Buchanan y Doyle, 1997). Entre estas cepas, ECEH, E. coli O157:H7 es el tipo más común (Wang et al., 2013).

Actualmente, los consumidores no sólo prestan más atención al riesgo de patógenos trasmitidos por los alimentos, sino también a la presencia de conservantes químicos artificiales para controlar dichos patógenos. Como resultado, los consumidores exigen un mayor uso de ingredientes naturales para garantizar la seguridad de los productos alimenticios (Ibrahim et al., 2008). Algunos de estos ingredientes pueden ser las especias culinarias, que incluyen hojas, flores, bulbos, frutos, tallos y otras partes de la planta (Shelef, 1983).

Tradicionalmente, las especias se han utilizado como agentes colorantes y aromatizantes de los alimentos en muchas partes del mundo (Lee et al., 2004); sin embargo, también se destacan por sus potenciales efectos antimicrobianos (Singh et al., 2002; Valero y Salmeron, 2003). La eficacia antimicrobiana de las especias depende del tipo de especia, su composición y concentración, tipo y concentración del microorganismo que se va a tratar, composición del sustrato y condiciones de procesamiento y almacenamiento del alimento (Leite et al., 2006). Por su parte, la actividad antimicrobiana se debe a muchos fitoquímicos activos, tales como compuestos fenólicos, flavonoides, terpenoides y carotenoides (Gharibi et al., 2013).
En este estudio, se evaluó el efecto antibacteriano de tres aditivos comestibles elaborados a base de especias culinarias sobre el crecimiento de Escherichia coli O157:H7 inoculada en hamburguesas de carne de cerdo cruda.

\section{Materiales Y MÉTOdos}

\section{Elaboración de aditivos}

La elaboración de los aditivos consistió, primeramente, en una mezcla de canela y clavo, la cual se obtuvo de macerar dicha mezcla por $24 \mathrm{~h}$ en ron de caña ( $40 \%$ de alcohol); enseguida, la mezcla se licuó con cada uno de los ingredientes (cuadro 1) que integran los aditivos hasta obtener una consistencia pastosa. La pasta fue centrifugada y el sobrenadante obtenido fue utilizado para el análisis de compuestos fenólicos totales (CFT), así como para el análisis in vitro, y para su aplicación en un sistema modelo de hamburguesas de carne cruda de cerdo con el fin de evaluar su actividad antibacteriana.

Cuadro 1. Ingredientes de los aditivos 1, 2 y 3.

\begin{tabular}{|c|c|c|}
\hline Aditivo $1_{1}$ & Aditivo $_{2}$ & Aditivo $_{3}$ \\
\hline Cebolla & Cebolla & Cebolla \\
\hline Cilantro & Cilantro & Cilantro \\
\hline Orégano & Hojas de laurel & Pimienta negra \\
\hline $\begin{array}{l}\text { Jugo de } \\
\text { limón }\end{array}$ & Jugo de limón & Chile verde \\
\hline \multirow[t]{5}{*}{$\begin{array}{c}\text { Mezcla } \\
\text { canela-clavo }\end{array}$} & $\begin{array}{c}\text { Mezcla canela- } \\
\text { clavo }\end{array}$ & Ajo \\
\hline & & Sal \\
\hline & & $\begin{array}{c}\text { Cálices de } \\
\text { jamaica verde } \\
\text { (variedad UAN- } \\
4 \text { ) }\end{array}$ \\
\hline & & Jugo de limón \\
\hline & & $\begin{array}{c}\text { Mezcla canela- } \\
\text { clavo }\end{array}$ \\
\hline
\end{tabular}

\section{Determinación de compuestos fenólicos totales}

Los compuestos fenólicos totales se determinaron de acuerdo al método de Stintzing et al. (2005). La técnica se inició colocando $100 \mu \mathrm{L}$ de muestra en viales 
eppendorf (por triplicado); se agregaron $500 \mu \mathrm{L}$ de solución Folin-Ciocalteu (1:10 en agua destilada) y 400 $\mu \mathrm{L}$ de carbonato de sodio (a $7.5 \%$ ); inmediatamente después, la muestra se agitó en vortex y se incubó a temperatura ambiente $\left(25^{\circ} \mathrm{C} \pm 1\right)$ durante 30 minutos. $\mathrm{Al}$ término del tiempo se midió la absorbancia a una longitud de onda de $765 \mathrm{~nm}$ en un espectrofotómetro (Power Wave XS, Biotek, Winooski, VT, USA).

\section{Preparación del inóculo}

La cepa aislada de Escherichia coli O157:H7 (código ATCC (American Type Culture Collection) fue obtenida del Laboratorio Estatal de Salud Pública del Estado de Nayarit y se sembró en caldo de soya tripticaseina (CST) (DIBICO, D.F., México) a una concentración de $1 \mathrm{~mL}$ del inóculo/100 mL de caldo a 37 ${ }^{\circ} \mathrm{C}$ por $24 \mathrm{~h}$ para asegurar su crecimiento (activación) (García-Guardado, 2011).

\section{Elaboración de sistemas modelo de hamburguesas de carne cruda de cerdo}

Con carne de cerdo (músculo longissimus dorsi) adquirida en una carnicería local de Tepic, Nayarit, se desarrollaron sistemas modelo tipo hamburguesa de acuerdo con las especificaciones descritas en el cuadro 2.

Cuadro 2. Formulación para la elaboración de sistemas modelo tipo hamburguesa de carne cruda de cerdo.

\begin{tabular}{|c|c|c|}
\hline \multirow{2}{*}{ INGREDIENTE } & \multicolumn{2}{|c|}{ Porcentaje } \\
\hline & Control & Tratados \\
\hline Lomo de cerdo & 80 & 80 \\
\hline Grasa dorsal & 10 & 10 \\
\hline Sal & 1 & 1 \\
\hline Agua & 9 & 4.5 \\
\hline Aditivo acuoso & 0 & 4.5 \\
\hline
\end{tabular}

La elaboración de las hamburguesas consistió en moler la carne y la grasa en un molino de carne (M-12-FS ${ }^{\circledR}$, Torrey, México); una vez molida la carne, se mezclaron la sal, el agua y el aditivo hasta obtener una mezcla homogénea. Ésta se envasó en bolsas de plástico transparente, las cuales fueron sometidas al alto vacío para eliminar las burbujas de aire internas que se pudieran formar. A partir de la mezcla obtenida, se pesaron porciones de $60 \mathrm{~g}$ de masa $\mathrm{y}$, con ayuda de un aro metálico de $8 \mathrm{~cm}$ de diámetro, se elaboraron los sistemas modelo tipo hamburguesas.

\section{Evaluación antimicrobiana de los aditivos in vitro}

La actividad antimicrobiana de los aditivos fue determinada por medio de un lector de microplacas (Multiskan $\mathrm{GO}^{\circledR}$, ThermoFisher Scientific, Estados Unidos). Con éste se midió la absorbancia a $600 \mathrm{~nm}$ de los pocillos, los cuales contenían $200 \mu \mathrm{L}$ de caldo soya tripticaseina con el inóculo a una concentración de $10^{5} \mathrm{UFC} / \mathrm{mL}$, y $50 \mu \mathrm{L}$ del aditivo, por $24 \mathrm{~h}$ a temperatura de $37^{\circ} \mathrm{C}$. Las lecturas se realizaron cada hora y las microplacas se agitaron por $30 \mathrm{~s}$ antes de cada medición (Rufián-Henares y Morales, 2008).

Evaluación antimicrobiana de los aditivos aplicados en hamburguesas de carne cruda de cerdo inoculadas en Escherichia coli

El análisis consistió en preparar 2 L de suspensión de células de E. coli a una concentración de $10^{5} \mathrm{UFC/}$ $\mathrm{mL}$ en una solución isotónica a $0.8 \%$ como medio de infección para las hamburguesas. Enseguida, las hamburguesas fueron impregnadas por ambos lados con el medio de infección mediante la ayuda de una brocha de plástico. Posteriormente, fueron colocadas en recipientes de plásticos transparentes y refrigerados a $4{ }^{\circ} \mathrm{C} \pm 2$ por un periodo de 12 días. Se realizaron muestreos los días $0,1,3,6,9$ y 12 . La toma y manejo de las muestras se realizó con base en la NOM-109-SSA1-1994 (SS, 1994a), mientras que la preparación y dilución de las muestras conforme a la NOM-110-SSA-1994 (SS, 1994b). Para evaluar la presencia de E. coli, se empleó agar Salmonella Shigella, utilizando una temperatura de incubación de $37^{\circ} \mathrm{C}$ durante $24 \mathrm{~h}$.

\section{Evaluación de color de las hamburguesas de carne cruda de cerdo inoculadas en Escherichia coli}

Para determinar el deterioro del color de la carne por microorganismos a lo largo del tiempo, se realizaron evaluaciones de color por medición instrumental (CIE, 1978) con ayuda de un colorímetro (Konica Minolat ${ }^{\circledR}$, Japón) en la superficie de las hamburguesas de carne 
de cerdo cruda inoculadas en el medio de infección ( $E$. coli) y tratadas con los aditivos, los días $0,1,3,6,9$ y 12 de almacenamiento en refrigeración a $4{ }^{\circ} \mathrm{C} \pm 2$. Las mediciones se realizaron por triplicado en tres zonas distintas elegidas aleatoriamente y a temperatura ambiente $\left(\approx 25^{\circ} \mathrm{C}\right)$. Se utilizó el sistema de medida de color CIE-L*a* $\mathrm{b}^{*}$, que define el color con la utilización de los tres componentes: $L^{*}$ determina la intensidad de la luminosidad ( $L^{*}=0$ oscuro; $L^{*}=100$ luminoso); los parámetros $\mathrm{a}^{*} \mathrm{y} \mathrm{b}^{*}$ fueron utilizados para calcular el ángulo hue $\left({ }^{\circ} \mathrm{h}\right)$ como lo indican García-Tejeda et al. (2011): $h=\tan -1\left(b^{*} / a^{*}\right)$, cuando $a^{*}>0$ y $b^{*} \geq 0$ o $h=180+$ $\tan -1\left(b^{*} / a^{*}\right)$ cuando $a^{*}<0$.

\section{Análisis estadístico}

Los resultados de los parámetros evaluados se realizaron mediante un análisis de varianza (ANDEVA). Cuando el análisis fue significativo $(p \leq 0.05)$, se realizó una prueba de comparación de medias con el fin de establecer las diferencias existentes entre cada grupo mediante la prueba de Tukey. Se utilizó el paquete estadístico Minitab v. 16.0.

\section{RESULTADOS Y DISCUSIóN}

\section{Compuestos fenólicos totales}

Los aditivos empleados en esta investigación se elaboraron con especias culinarias referidas por su alto contenido de compuestos fenólicos y actividad antimicrobiana (Brewer, 2011; Hinneburg et al., 2006; Hirasa y Takemasa, 2002; Lv et al., 2012; Muchuweti et al., 2007; Vallverdú-Queralt et al., 2014). Asimismo, el contenido de fenoles totales y actividad antibacteriana de los cálices de jamaica ya ha sido señalado por diversas investigaciones (Alshami y Alharbi, 2014; Higginbotham et al., 2014; Sulaiman et al., 2014).

Los resultados del CFT de los tres aditivos (figura 1) señalan que todos poseen presencia de compuestos bioactivos. El aditivo 3 fue el que presentó la mayor concentración. Sin embargo, los otros dos no lograron inhibir el crecimiento bacteriano al ser aplicados en el sistema modelo de hamburguesas, aunque contuviesen CFT.

\section{Actividad antimicrobiana de los aditivos in vitro}

La actividad antimicrobiana in vitro de los aditivos 1 , 2 y 3 muestra un efecto bacteriostático (figura 2). Los tres aditivos analizados lograron reducir la velocidad

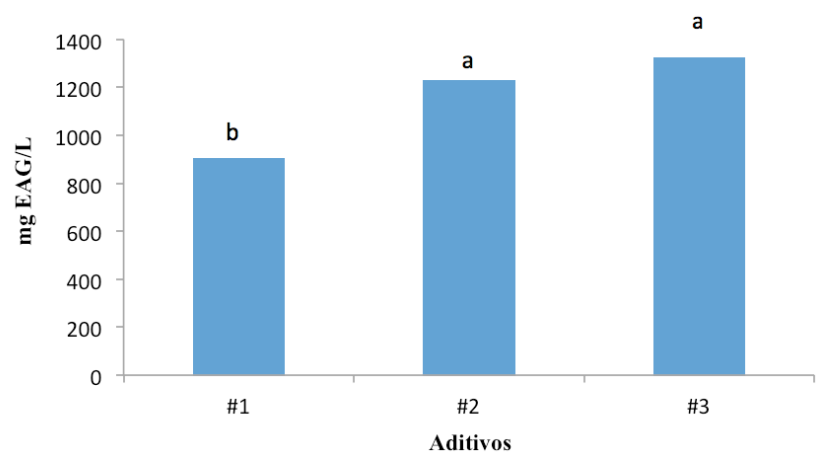

* Medias con superíndice distinto son significativamente diferentes $(p \leq 0.05)$ (ANDEVA).

Figura 1. Concentración de compuestos fenólicos totales de tres aditivos.

de crecimiento bacteriano en comparación con la muestra control. El aditivo 3 logró reducir la velocidad de crecimiento microbiano en $41.20 \%$, mientras que los aditivos 1 y 2 , en 38.85 y $23.38 \%$, respectivamente. Lo anterior significa que, con la aplicación de los aditivos, el tiempo exponencial o de duplicación bacteriana disminuyó $12 \mathrm{~h}$ aproximadamente para los aditivos 1 y $3,9 \mathrm{~h}$ para el aditivo 2, y $7 \mathrm{~h}$ para la muestra control, lo cual podría indicar que el aditivo 3 muestra un mejor efecto. Sin embargo, entre los tres aditivos no se presentó diferencia significativa $(\mathrm{p} \leq 0.05)$, lo que indica que los tres aditivos tienen el mismo efecto bacteriostático sobre Escherichia coli O157:H7.

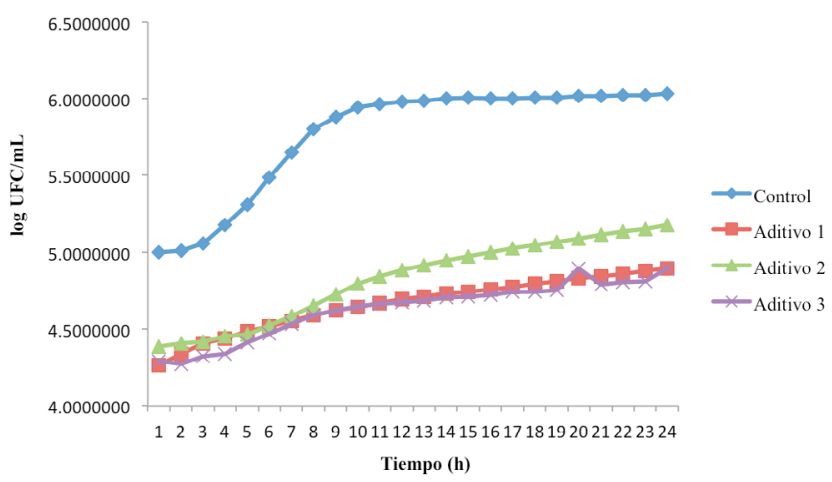

Figura 2. Efecto de los aditivos sobre la concentración de $E$. coli en CST durante $24 \mathrm{~h}$ a $37^{\circ} \mathrm{C}$.

La actividad bacteriostática de los tres aditivos estudiados frente a Escherichia coli O157:H7 se puede deber a los fitoquímicos activos presentes en las especias que los integran, tales como ácidos 
fenólicos, flavonoides y terpenoides, cuya actividad antimicrobiana ha sido reportada (Gharibi et al., 2013; Shan et al., 2007). La eficacia de los compuestos polifenólicos podría atribuirse a su interacción con la membrana celular de los microorganismos. Estos compuestos podrían inhibir las actividades de proteasas y proteínas transportadoras, que podrían afectar a las funciones bacterianas (Kchaou et al., 2016; Reygaert, 2014).

Por otra parte, Hirasa y Takemasa (2002) afirman que los compuestos polifenólicos con un grupo hidroxilo $(-\mathrm{OH})$ o un grupo aldehído $(-\mathrm{CHO})$ tienden a poseer una fuerte actividad antimicrobiana. El grupo hidroxilo puede formar enlaces de hidrógeno con el sitio activo de una enzima, lo que ocasiona su desactivación. A su vez, se considera que la inhibición del crecimiento por el grupo aldehído puede deberse, en parte, a sus reacciones con los grupos sulfhidrilo, necesarios para el crecimiento microbiano (Farag et al., 1989).

\section{Actividad antimicrobiana de los aditivos aplicados en hamburguesas de carne cruda de cerdo}

Sólo el aditivo 3 mostró actividad bacteriostática estable a lo largo de los 12 días de almacenamiento (figura 3), aunque sin diferencia significativa con la muestra sin inóculo (cuadro 3), pero registrando reducción del crecimiento microbiano. Por otra parte, el aditivo 3, a partir del día 3 de almacenamiento, registró valores menores que la muestra sin aditivo, lo que resultó significativo $(p \leq 0.05)$ el día 9 (cuadro 3). Sin embargo, debido a la alta cantidad de bacterias inoculadas, la vida útil de la carne cruda de cerdo se redujo al día 9 de almacenamiento ya que, a partir de ese día, se perdieron características sensoriales de calidad deseables en la carne (color y olor). En relación con los aditivos 1 y 2, éstos no mostraron un efecto bacteriostático de manera significativa, que se presentó antes de la fase exponencial (día 6) en comparación con la muestra sin aditivo (día 9).

La efectividad bacteriostática del aditivo 3 mostrada en el análisis in vitro se conservó para el sistema modelo de hamburguesas. Ésta puede haberse debido a la alta presencia de fitoquímicos activos en los ingredientes que integran al aditivo 3 , tales como ácidos fenólicos, flavonoides y terpenoides, en los cuales se ha reportado actividad antimicrobiana (Gharibi et al., 2013; Shan et al., 2007) y capacidad de inhibir el metabolismo celular de los microorganismos causando alteraciones en la membrana celular de éstos (Kchaou et al., 2016; Reygaert, 2014).

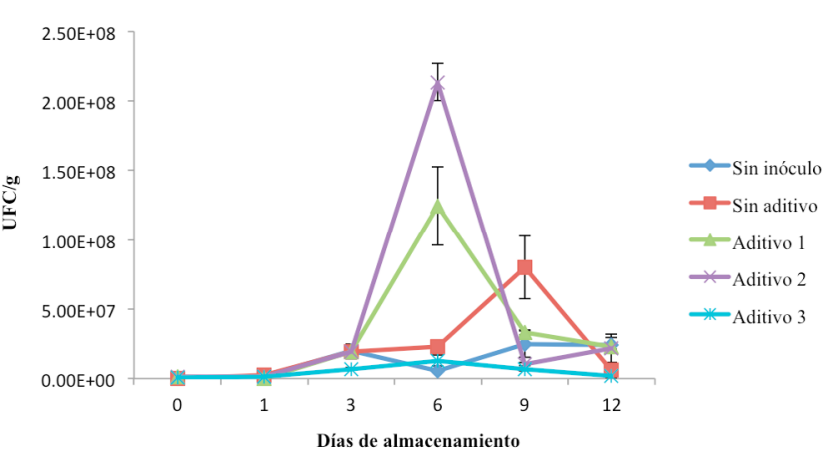

Figura 3. Efecto de los aditivos sobre la concentración de $E$. coli en hamburguesas de carne cruda de cerdo almacenadas a $4^{\circ} \mathrm{C}$ durante 12 días.

Dentro de los ingredientes que integran al aditivo 3 y que no están presentes en los aditivos 1 y 2 , se encuentran la jamaica, el ajo y la pimienta negra. La actividad antimicrobiana de estos ingredientes ha sido reportada por diversos investigadores: Sulaiman et al. (2014) compararon la actividad antimicrobiana del ajo (Allium sativum L.), la jamaica (Hibiscus sabdariffa L.) y el jengibre (Zingiber officinale Roscoe), así como la combinación de los tres, contra Escherichia coli, atribuyendo su efectividad al contenido de flavonoides, terpenoides, alcaloides, taninos, saponinas, antraquinonas y compuestos fenólicos. Higginbotham et al. (2014) utilizaron extractos de jamaica como un aditivo en salchichas para inhibir la reproducción de Listeria monocytogenes y Staphylococcus aureus resistente a la meticilina, y concluyeron que es altamente efectivo para la inhibición de estas especies bacterianas y que, a mayor concentración y tiempo de inmersión, mejor fue el efecto antimicrobiano. Por otro lado, Huhtanen (1980) probó extractos etanólicos de 33 especias contra Clostridium botulinum y encontró que la nuez moscada, el laurel y la pimienta negra mostraron fuerte actividad inhibidora frente a esta bacteria, mientras que otras especias como el ajo exhibieron escasa o nula actividad a una concentración de 2000 ppm.

Algunas especias se usan rutinariamente en productos cárnicos y es probable que actúen en ellos inhibiendo el crecimiento bacteriano, dependiendo de las cantidades empleadas en la formulación (Hirasa y Takemasa, 2002). El crecimiento significativo $(p \leq 0.05)$ de E. coli con los aditivos 1 y 2 puede deberse a diferentes factores; entre ellos, la concentración. Hirasa y Takemasa (2002) señalan que las propiedades antimicrobianas de un extracto etanólico de wasabi 
Cuadro 3. Medias de UFC por g de hamburguesas de carne cruda de cerdo inoculadas con Escherichia coli O157:H7 almacenadas a $4{ }^{\circ} \mathrm{C}$ durante 12 días.

\begin{tabular}{ccccccc}
\hline \multicolumn{7}{c}{ DíAS } \\
\hline MuESTRAS & $\mathbf{0}$ & $\mathbf{1}$ & $\mathbf{3}$ & $\mathbf{6}$ & $\mathbf{9}$ & $\mathbf{1 2}$ \\
\hline Sin inóculo & $1.20 \mathrm{E}+04^{\mathrm{b}}$ & $2.20 \mathrm{E}+06^{\mathrm{a}}$ & $1.98 \mathrm{E}+07^{\mathrm{a}}$ & $5.70 \mathrm{E}+06^{\mathrm{c}}$ & $2.48 \mathrm{E}+07^{\mathrm{b}}$ & $2.43 \mathrm{E}+07^{\mathrm{a}}$ \\
Sin aditivo & $4.17 \mathrm{E}+04^{\mathrm{b}}$ & $2.45 \mathrm{E}+06^{\mathrm{a}}$ & $1.95 \mathrm{E}+07^{\mathrm{a}}$ & $2.27 \mathrm{E}+07^{\mathrm{c}}$ & $8.00 \mathrm{E}+07^{\mathrm{a}}$ & $5.92 \mathrm{E}+06^{\mathrm{a}}$ \\
Aditivo 1 & $1.15 \mathrm{E}+06^{\mathrm{a}}$ & $4.67 \mathrm{E}+04^{\mathrm{b}}$ & $1.91 \mathrm{E}+07^{\mathrm{a}}$ & $1.25 \mathrm{E}+08^{\mathrm{b}}$ & $3.30 \mathrm{E}+07^{\mathrm{ab}}$ & $2.27 \mathrm{E}+07^{\mathrm{a}}$ \\
Aditivo 2 & $1.39 \mathrm{E}+06^{\mathrm{a}}$ & $1.41 \mathrm{E}+06^{\mathrm{ab}}$ & $1.95 \mathrm{E}+07^{\mathrm{a}}$ & $2.14 \mathrm{E}+08^{\mathrm{a}}$ & $1.03 \mathrm{E}+07^{\mathrm{b}}$ & $2.15 \mathrm{E}+07^{\mathrm{a}}$ \\
Aditivo 3 & $7.77 \mathrm{E}+05^{\mathrm{ab}}$ & $1.05 \mathrm{E}+06^{\mathrm{ab}}$ & $6.90 \mathrm{E}+06^{\mathrm{a}}$ & $1.29 \mathrm{E}+07^{\mathrm{c}}$ & $6.55 \mathrm{E}+06^{\mathrm{b}}$ & $2.13 \mathrm{E}+06^{\mathrm{a}}$ \\
\hline
\end{tabular}

* Medias con súper índice distinto son significativamente diferente (por columna) ( $p \leq 0.05)$ (ANDEVA).

sobre E. coli aumentaban al incrementar las cantidades añadidas; asimismo, Xiong et al. (2017) señalaron que el galato de epigalatoecatequina presente en el té verde mostró actividad antibacteriana contra E. coli en una manera dependiente de la dosis.

En el presente trabajo los aditivos estudiados se diluyeron en $50 \%$ (debido a que el aditivo concentrado impartía en las hamburguesas un sabor demasiado intenso). Este factor pudo haber influido en que no se llevara a cabo una actividad eficaz antimicrobiana con los aditivos 1 y 2 , ya que es probable que no se haya logrado un balance entre los compuestos fitoquímicos antimicrobianos y los nutrientes para el crecimiento bacteriano y que, por ende, haya existido una mayor disponibilidad de nutrientes que de compuestos antibacterianos. Asimismo, cabe señalar que la concentración de bacterias de $E$. coli inoculadas en las muestras podría considerarse alta $\left(10^{5} \mathrm{UFC} / \mathrm{mL}\right)$, de manera que los compuestos antibacterianos pudieron no ser suficientes. Por otra parte, las bacterias gram-negativo (E. coli) suelen ser más resistentes al ataque de compuestos antibacterianos debido a que poseen una membrana lipídica externa de protección adicional a la membrana citoplasmática (Bamoniri et al., 2010; Kossah et al., 2011).

Hasta el momento, son pocos los estudios que reflejan un aumento en el crecimiento de $E$. coli a base de especias culinarias. Noda et al. (1985) indicaron que el jugo de ajo promovía el crecimiento de dicho microrganismo y era dependiente de la concentración: a una dilución de 750 veces no se observó crecimiento de E. coli, pero la bacteria se encontró a diluciones en el rango de 15000 a 150000 veces. Se discrepó que la escordinina, un constituyente fitoquímico, tenía capacidad para promover el crecimiento de E. coli. Asimismo, señalaron que, a bajas concentraciones, el ácido tánico presente en el tomillo y el ácido ascórbico presente en varias especias frescas actuaron como factores de promoción en el crecimiento de E. coli.

\section{Color en hamburguesas de carne cruda de cerdo recubiertas con aditivo e inoculadas con Escherichia coli}

El color o tonalidad en la carne de un animal de abastecimiento es uno de los atributos de mayor importancia para los consumidores al momento de adquirir un producto fresco (Francis y Clydesdale, 1975). El análisis de los resultados no mostró diferencia significativa $(p \leq 0.05)$ entre los tratamientos con respecto al parámetro de luminosidad (figura 4). Todas las muestras presentaron una luminosidad media, que osciló entre 45 y 57 a lo largo de los 12 días de almacenamiento. Para el caso de las hamburguesas con aditivos, lo anterior se puede deber a que el color propio de éstos haya restado luminosidad o brillantez particular a la carne. Asimismo, se pudo deber al deterioro microbiano, que se produce cuando los nutrientes de la carne, como glucosa, aminoácidos libres y compuestos volátiles, son metabolizados durante el crecimiento bacteriano, lo que contribuye al desarrollo de colores desagradables, así como malos olores y sabores (Cappelletti et al., 2015; Tang et al., 2013; Nychas et al., 2008). El deterioro microbiano también pudo haber sido la causa para las hamburguesas sin aditivo pues cabe señalar que la inoculación se realizó con una alta carga microbiana $\left(10^{5} \mathrm{UFC} / \mathrm{mL}\right)$ mientras que, para las hamburguesas sin inóculo, esto se pudo deber a la propia carga microbiana implícita ya en la carne.

En relación con el ángulo matiz, indicativo del color (García-Tejeda et al., 2011), los resultados obtenidos (figura 5) presentaron diferencia significativa $(p \leq 0.05)$ entre los tratamientos durante los tres primeros días de almacenamiento refrigerado. Los aditivos 1 y 3 no lograron inhibir la decoloración de la carne de cerdo cruda pues presentaron valores significativamente más altos $(p \leq 0.05)$ que las hamburguesas sin inóculo, sin aditivo y con aditivo 2 ; se situaron en una tonalidad 


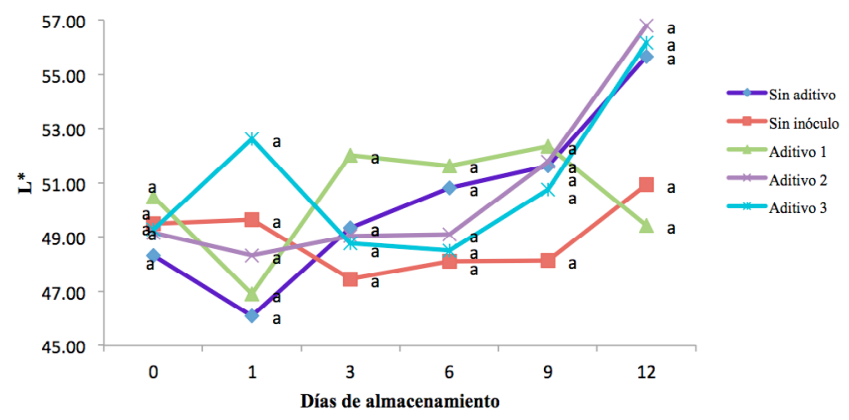

* Medias con superíndice distinto son significativamente diferentes $(p \leq 0.05)$ (ANDEVA).

Figura 4. Efecto de los aditivos sobre la luminosidad o brillantez de las hamburguesas de carne cruda de cerdo inoculadas con E. coli y almacenadas a $4^{\circ} \mathrm{C}$ durante 12 días.

de rangos naranja tenues debido al color propio de los aditivos. A su vez, el aditivo 2 no presentó diferencia significativa $(p \leq 0.05)$ en relación con las hamburguesas sin inóculo y sin aditivo, por lo que se puede decir que ninguno de los aditivos logró inhibir la decoloración de la carne cruda de cerdo. Cabe recalcar que, a partir del día seis de almacenamiento, todas las muestras (con excepción de la muestra con aditivo 1) comenzaron a mostrar un aumento en sus valores, tomando tonalidades amarillas, sin presentar diferencia significativa entre ellas. La decoloración o tonalidad amarillosa de la carne puede deberse a una ausencia de sustratos carbohidratados fácilmente disponibles. Al suceder esto, los microorganismos atacan inmediatamente a los aminoácidos causando una alteración que se manifiesta con olores desagradables y cambios de coloración (Newton y Gill, 1978). La decoloración también puede deberse a procesos oxidativos que provocan la degradación de lípidos y proteínas presentes en la carne (Chelh et al., 2007), con lo cual inician el deterioro de su calidad sensorial.

\section{Conclusiones}

El aditivo 3 fue capaz de reducir el crecimiento bacteriano de una alta concentración de E. coli (105 $\mathrm{UFC} / \mathrm{mL}$ ) en hamburguesas de carne cruda de cerdo, aun diluyéndolo a $50 \%$ de su concentración original. Sin embargo, ninguno de los tres aditivos analizados logró inhibir la decoloración de la carne ni mejorar su brillantez.

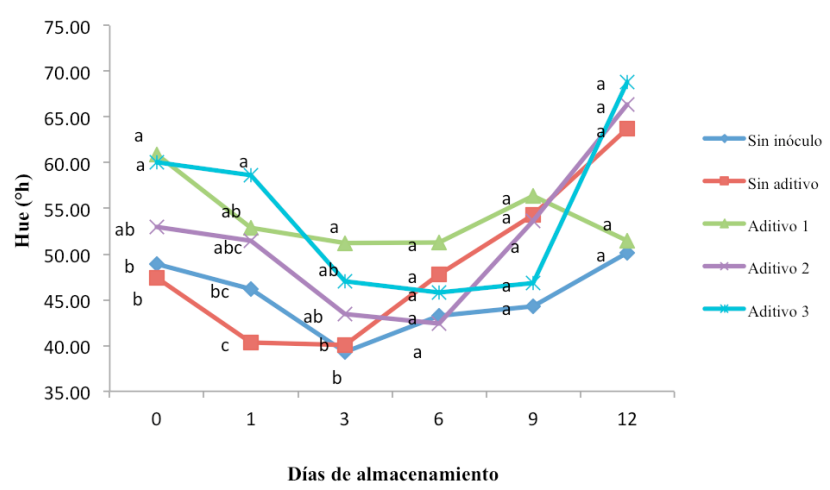

* Valores de media con superíndice distinto son significativamente diferentes $(p \leq 0.05)$ (ANDEVA).

Figura 5. Efecto de los aditivos sobre el color de las hamburguesas de carne cruda de cerdo inoculadas con E. coli y almacenadas a $4^{\circ} \mathrm{C}$ durante 12 días.

\section{Agradecimientos}

Al Dr. Pedro Ulises Bautista Rosales, al Dr. Javier Germán Rodríguez Carpena y al M. en C. Yolotzin Apatzingán Palomino Hermosillo, así como al estudiante de posgrado I. en A. Gibrán López Nahuatt (Universidad Autónoma de Nayarit), por el apoyo que brindaron para la realización de esta investigación. 


\section{LiTERATURA CITADA}

Alshami, I., A. E. Alharbi. 2014. Hibiscus sabdariffa extract inhibits in vitro biofilm formation capacity of Candida albicans isolated from recurrent urinary tract infections. Asian Pacific Journal of Tropical Biomedicine 4: 104108.

Bamoniri, A., A. H. Ebrahimabadi, A. Mazoochi, M. Behpour, F. Jookar Kashi, H. Batooli. 2010. Antioxidant and antimicrobial activity evaluation and essential oil analysis of Semenovia tragioides Boiss from Iran. Food Chemistry 112: 553-558.

Brewer, M. S. 2011. Natural Antioxidants: Sources, Compounds, Mechanisms of Action, and Potential Applications. Comprehensive Reviews in Food Science and Food Safety 10: 221-247.

Buchanan, R. L., M. P. Doyle. 1997. Foodborne disease significance of Escherichia coli O157:H7 and other enterohemorrhagic E. coli. Food Technology 51(10): 69-76.

Cappelletti, M., G. Ferrentino, S. Spilimbergo. 2015. High pressure carbon dioxide on pork raw meat: Inactivation of mesophilic bacteria and effects on colour properties. Journal of Food Engineering 156: 55-58.

Comission Internationale de l'Éclairage (CIE). 1978. Recommendations on uniform color spaces-color equations, psychometric color terms. Supp nr 2 to CIE Publ nr 15 (E-1.3.L) 1971 (9TC-1-3), Paris, France: CIE.

Chelh, I., P. Gatellier, V. Sante-Lhoutellier. 2007. Characterisation of fluorescent Schiff bases formed during oxidation of pig myofibrils. Meat Science 76: 210-215.

Farag, S. R., Z. Y. Daw, S. H. Abo-Raya. 1989. Influence of some spice essential oils on Aspergillus parasiticus growth and production of aflatoxins in a synthetic medium. Journal of Food Science 54(1): 74-76.

Francis, F. J., F. M. Clydesdale. 1975. Food Colorimetry: Theory and Applications. The AVI Publishing Company Inc. Connecticut, USA. 486 pp.

García-Guardado, A. 2011. Inactivación de Escherichia coli O157:H7 mediante la aplicación de altas presiones en jugo de maracuyá. Tesis de Maestría. Instituto Tecnológico de Tepic. 64 pp.

García-Tejeda, Y. V., P. B. Zamudio-Flores, L. A. Bello-Pérez, C. A. Romero-Bastida, J. Solorza-Feria. 2011. Oxidación del almidón nativo de plátano para su uso potencia en la fabricación de materiales de empaque biodegradables: Caracterización física, química, térmica y morfológica. Revista Iberoamericana de Polímeros 12(3): 125-135.

Gharibi, S. H., B. E. S. Tabatabaei, G. H. Saeidi, S. A. H. Goli. 2013. Evaluation of total phenolic content and antioxidant activity of three novel Iranian endemic Achillea species. Industrial Crops and Products 50: 154-158.

Higginbotham K. L. A., K. P. Burris, S. Zivanovic, P. M. Davidson, C. N. Stewart. 2014. Aqueous extracts of $\mathrm{Hi}$ biscus sabdariffa calyces as an antimicrobial rinse on hot dogs against Listeria monocytogenes and methicillin-resistant Staphylococcus aureus. Food Control 40: 274-277.
Hinneburg, I., D. Dorman, R. Hiltunen. 2006. Antioxidant activities of extracts from selected culinary herbs and spices. Food Chemistry 97(1): 122-129.

Hirasa K., M. Takemasa. 2002. Ciencia y tecnología de las especias. Editorial Acribia, S. A. Zaragoza, España. 250 pp.

Huhtanen, C. N. 1980. Inhibition of Clostridium botulinum by spice extracts and aliphatic alcohols. Journal of Food Protection 43: 195-197.

Ibrahim, S. A., H. Yang, W. S. Chung. 2008. Antimicrobial activity of lactic acid and copper on growth of Salmonella and Escherichia coli O157:H7 in laboratory medium and carrot juice. Food Chemistry 109: 137-143.

Kchaou, W., F. Abbès, R. B. Mansour, C. Blecker, H. Attia, S. Besbes. 2016. Phenolic profile, antibacterial and cytotoxic properties of second grade date extract from Tunisian cultivars (Phoenix dactylifera L.). Food Chemistry 194: 1048-1055.

Kossah, R., H. Zhang, W. Chen. 2011. Antimicrobial and antioxidant activities of Chinese sumac (Rhus typhina L.) fruit extract. Food Control 22: 128-132.

Lee K. W., H. Everts, A. C. Beynen. 2004. Essential oils in broiler nutrition. International Journal of Poultry Science 3: 738-752.

Leite de Souza, E., N. B. Guerr., T. L. M. Stamford, E. O. Lima. 2006. Spices: alternative sources of antimicrobial compounds to use in food conservation. Revista Brasileira de Farmácia 87: 22-25.

Lv, J., H. Huang, L. Yu, M. Whent, Y. Niu, H. Shi, T. T. Y. Wang, D. L. Luthria, D. Charles, L. L. Yu. 2012. Phenolic composition and nutraceutical properties of organic and conventional cinnamon and peppermint. Food Chemistry 132: 1442-1450.

Mead P. S., L. Slutsker, V. Dietz. 1999. Food related illness and dead in the United States. Emerging Infectious Diseases 5: 607-625.

Muchuweti, M., E. Kativu, C. H. Mupure, C. Chidewe, A. R. Ndhlala, M. A. N. Benhura. 2007. Phenolic composition and antioxidant properties of some spices. American Journal of Food Technology 2(5): 414-420.

Newton, K. G., C. O. Gill. 1978. Development of bacterial spoilage at adipose tissue surfaces of fresh meat. Applied and Environmental Microbiology 39(5): 10761077.

Noda, K., S. Isozaki, H. Taniguchi. 1985. Growth promoting and inhibiting effects of spices on Escherichia coli. Nippon Shokuhin Kogyo Gakkaishi 32(11): 791-796.

Nychas, G. J. E., P. N. Skandamis, C. C. Tassou, K. P. Koutsoumanis. 2008. Meat spoilage during distribution. Meat Science 78: 77-89.

Reygaert, W. C. 2014. The antimicrobial possibilities of green tea. Frontiers in Microbiology 5(434): 1-8.

Rufián-Henares, J. A., F. J. Morales. 2008. Microtiter plate-based assay for screening antimicrobial activity of melanoidins against E. coli and S. aureus. Food Chemistry 111: 1069-1074. 
Secretaría de Salud (SS). 1994a. NORMA OFICIAL MEXICANA NOM-109-SSA1-1994. Bienes y servicios. Procedimientos para la toma, manejo y transporte de muestras de alimentos para su análisis microbiológico. Fecha de Emisión en el DOF: 26 de mayo de 1994, México D.F. 1-5 pp.

Secretaría de Salud (SS) 1994b. NORMA OFICIAL MEXICANA NOM-110-SSA1-1994. Bienes y servicios. Preparación y dilución de muestras de alimentos para su análisis microbiológico. Fecha de Emisión en el DOF: 15 de agosto de 1994, México D. F. 1-5 pp.

Shan, B., Y. Z. Cai, J. D. Brooks, H. Corke. 2007. The in vitro antibacterial activity of dietary spice and medicinal herb extracts. International Journal of Food Microbiology 117: 112-119.

Shelef, L.A. 1983. Antimicrobial effects of spices. Journal of Food Safety 6: 29-44.

Singh, G., I. P. Kapoor., S. K. Pandey., U. K. Singh, R. K. Singh. 2002. Studies on essential oils: part 10; antibacterial activity of volatile oils of some spices. Phytotherapy Research 16: 680-682.

Stintzing, F. C., K. M. Herbach, M. R. Mosshammer, R. Carle, W. Yi, S. Sellappan, C. C. Akoh, R. Bunch, P. Felker. 2005. Color, betalin pattern, and antioxidant properties of cactus pear (Opuntia spp.) clones. Journal of Agricultural and Food Chemistry 53(2): 442-451.

Sulaiman, F.A., M. O. Kazeem, A. M. Waheed, S. O. Temowo, I. O. Azeez, F. I. Zubair, T. A. Adeyemi, A. Nyang, O. S. Adeyemi. 2014. Antimicrobial and toxic potential of aqueous extracts of Allium sativum, Hibiscus sabdariffa and Zingiber officinale in Wistar rats. Journal of Taibah University for Science 8: 315-322.

Tang, X., X. Sun, V. C. H. Wu, J. Xie, Y. Pan, Y. Zhao, P. K. Malakar. 2013. Predicting shelf-life of chilled pork sold in China. Food Control 32: 334-340.

United States Department of Agriculture (USDA). 1997. Consumer information. Food Safety and Inspection Service, Food Safety and Consumer Education Office.

Valero, M., M. C. Salmerón. 2003. Antibacterial activity of 11 essential oils against Bacillus cereus in tyndallized carrot broth. International Journal of Food Microbiology 85: 73-81.

Vallverdú-Queralt, A., J. Regueiro, M. Martinez-Huelamo, J. F. Rinaldi Alvarenga, L. Neto-Leal, R. M. Lamuela-Raventos. 2014. A comprehensive study on the phenolic profile of widely used culinary herbs and spices: Rosemary, thyme, oregano, cinnamon, cumin and bay. Food Chemistry 154: 299-307.

Viuda-Martos, M., N. G. S. El-Gendy., E. Sendra., J. Fernández-López., K. A. A. El-Razik., A. El-Sayed, J. A. Pérez-Álvarez. 2010. Chemical composition and antioxidant and anti-listeria activities of essential oils obtained from some Egyptian plants. Journal of Agricultural Food Chemistry 58: 9063-9070.
Wang F., Z. Jiang, Y. Li, X. He, J. Zhao, X. Yang, L. Zhu, Z. Yin, X. Li, X. Wang, W. Liu, W. Shang, Z. Yang, S. Wang, Q. Zhen, Z. Zhang, Y. Yu, H. Zhong, Q. Ye, L. Huang, J. Yuan. 2013. Shigella flexneri T3SS effector IpaH4.5 modulates the host inflammatory response via interaction with NF-B p65 protein. Cellular Microbioly 15: 474-485.

Xiong, L. G., Y. J. Chen, J. W. Tong, J. A. Huang, J. Li, Y. S. Gong, Z. H. Liu. 2017. Tea polyphenol epigallocatechin gallate inhibits Escherichia coli by increasing endogenous oxidative stress. Food Chemistry 217: 196-204. 